\title{
Caramels, sucre, respiració i velocitat de reacció
}

\author{
Basili Martínez Espinet $\bowtie$ \\ Institut Miquel Martí i Pol (Roda de Ter)
}

En aquest treball pràctic presentem una reacció que permet estudiar qualitativament els factors que determinen la velocitat d'una reacció química. Aquesta reacció es fa amb productes habituals al laboratori (sucre i permanganat) $i$ a més incorporem el xupa-xups per apropar la química al pensament quotidià de l'alumne. Utilitzem el permanganat com a reactiu limitant i quan acaba la reacció observem un canvi de color. Mesurant el temps que triga per canviar de color fem una estimació de la velocitat de la reacció i d'aquesta manera podem valorar els diferents factors.

Paraules clau: xupa-xups, sucre, permanganat, reacció redox, velocitat de reacció

\section{Objectius}

En aquest treball pràctic de laboratori, tenim per objectiu presentar una reacció química que ens permet estudiar qualitativament els factors dels quals depèn habitualment la velocitat de reacció.

Els reactius són el sucre i el permanganat de potassi, dos productes habituals en els nostres laboratoris.

La velocitat d'aquesta reacció depèn de la temperatura (tot i que la reacció és exotèrmica, cal escalfar per dur-la a terme), de la concentració dels reactius, del seu grau de divisió (el caramel ens serveix per aportar sucre amb un elevat grau de divisió), del seu estat físic (el sucre es pot introduir en estat sòlid o en forma de dissolució) i de la presència de catalitzadors. Si utilitzem el permanganat com a reactiu limitant, al final de la reacció observem un canvi de color que ens permet valorar l'efecte de les variables que anem introduint.

En aquesta reacció fem servir un caramel o un xupa-xups per mirar de captar l'atenció de l'alumne i apropar els fenòmens químics a la seva realitat quotidiana $\mathrm{i}$ al seu pensament habitual, de forma que s'adoni de la rellevància de la química en el desenvolupament de la vida.

Una de les preguntes que sol fer l'alumne és si al final es podrà menjar el xupa-xup, la resposta és que sí, passant-li una mica d'aigua i fent les coses amb cura i amb respecte vers el medi ambient.
Un altre aspecte important és el tractament $i$ desactivació del residu de manera que l'impacte del nostre experiment sigui mínim. Aquesta reacció crec que permet induir a l'alumne a reflexionar sobre la importància i la transversalitat de la química i el respecte que cal tenir envers el medi ambient quan utilitzem un instrument tan potent.

Aquesta reacció la podem fer servir tant a tercer com a quart d'ESO, on s'explica el concepte de velocitat de reacció i els factors que la determinen. També es pot fer servir a batxillerat variant el plantejament i el grau de complexitat.

L'oxidació del sucre per obtenir energia, diòxid de carboni i aigua, és la reacció bàsica que té lloc en la respiració cel-lular. Encara que aquí el mecanisme pel qual transcorre la reacció sigui una mica diferent, cal esmentar-ho com a fet transversal.

\section{Desenvolupament de l'experiència}

En aquest treball descriurem els processos i les quantitats exactes de reactius utilitzats perquè la pràctica funcioni i es puguin extreure les conclusions desitjades.

Aquesta pràctica permet, però, per la seva senzillesa, plantejar els fonaments teòrics als alumnes i proposar-los que ells mateixos dissenyin un experiment del qual en puguin treure conclusions. 
El sucre que farem servir, és la sacarosa; la seva fórmula és $\mathrm{C}_{12} \mathrm{H}_{22} \mathrm{O}_{11} \mathrm{i}$ la seva estructura tridimensional és la següent:

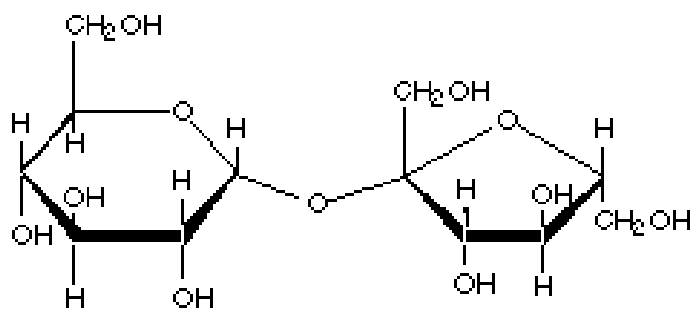

Figura 1. Estructura de la sacarosa.

La reacció que té $l l o c$ amb el permanganat de potassi és d'oxidació-reducció, ja que hi ha una transferència d'electrons. És exotèrmica i en medi àcid té una energia d'activació i per això cal escalfar el sistema si volem observar la reacció.

En la reacció el sucre fa el paper de reductor, ja que s'oxida i el permanganat el d'oxidant perquè es redueix. Els protons, tot i que ens apareixen com a reactiu en la reacció ajustada, no varien el seu estat d'oxidació.

La reacció és:

$$
\mathrm{H}^{+}+\mathrm{C}_{12} \mathrm{H}_{22} \mathrm{O}_{11}+\mathrm{MnO}_{4}^{-} \rightarrow \mathrm{Mn}^{2+}+\mathrm{CO}_{2(\mathrm{~g})}+\mathrm{H}_{2} \mathrm{O}
$$

Per ajustar-la fem servir el mètode de l'ió electró i finalment ens queda:

$$
\begin{gathered}
144 \mathrm{H}^{+}+5 \mathrm{C}_{12} \mathrm{H}_{22} \mathrm{O}_{11}+48 \mathrm{MnO}_{4}^{-} \rightarrow \\
\rightarrow 48 \mathrm{Mn}^{2+}+60 \mathrm{CO}_{2(\mathrm{~g})}+127 \mathrm{H}_{2} \mathrm{O}
\end{gathered}
$$
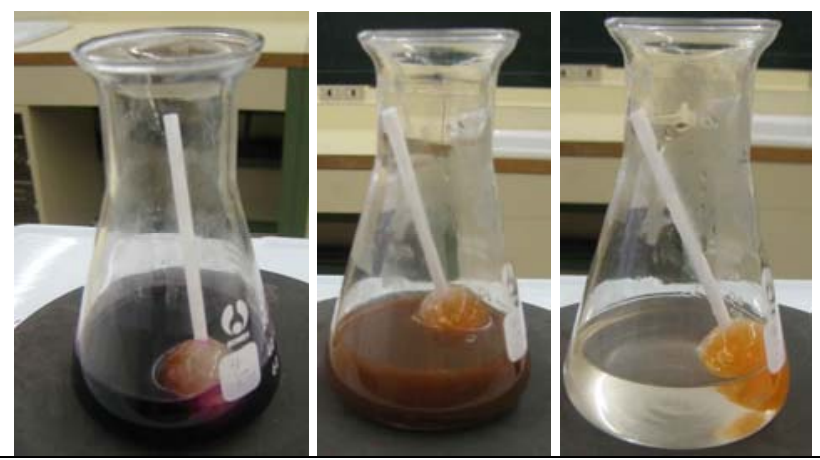

Figura 2. En les imatges podem observar l'evolució del color, en el temps de reacció.

Si observem les proporcions i hi apliquem les masses moleculars, suposant que l'àcid estigui en forma d'àcid sulfúric $\left(\mathrm{H}_{2} \mathrm{SO}_{4}\right)$ i el permanganat en forma de permanganat de potassi $\left(\mathrm{KMnO}_{4}\right)$, alesho- res $1 \mathrm{~g}$ de permanganat reacciona amb 0,22 $\mathrm{g}$ de sucre i necessita 0,93 g d'àcid sulfúric.

Nosaltres plantejarem la reacció de manera que el reactiu limitant sigui el permanganat que ens dóna un color violat fosc mentre hi és present; la mescla de reacció és incolora quan s'esgota el permanganat. Anirem fent-hi variacions, de forma que puguem anar-ne avaluant els diferents efectes.

\section{Reactius}

- Permanganat de potassi $(0,0125 \mathrm{~mol} / \mathrm{L})$. Es prepara dissolent en aigua destil-lada $2 \mathrm{~g}$ de permanganat de potassi cristal-litzat i diluint amb aigua destil-lada fins a un volum d'un litre.

- Àcid sulfúric 1:5. Es dilueix un volum d'àcid sulfúric $(100 \mathrm{~mL})$ en quatre volums d'aigua destil.lada (400 mL) amb molta cura.

- Sucre, xupa-xups, aigua destil·lada

\section{Material}

Fogó elèctric, cronòmetre, provetes de $25 \mathrm{~mL}$, erlenmeyers (bomex $200 \mathrm{~mL}$ ), vas de precipitats, balança (fig. 3).

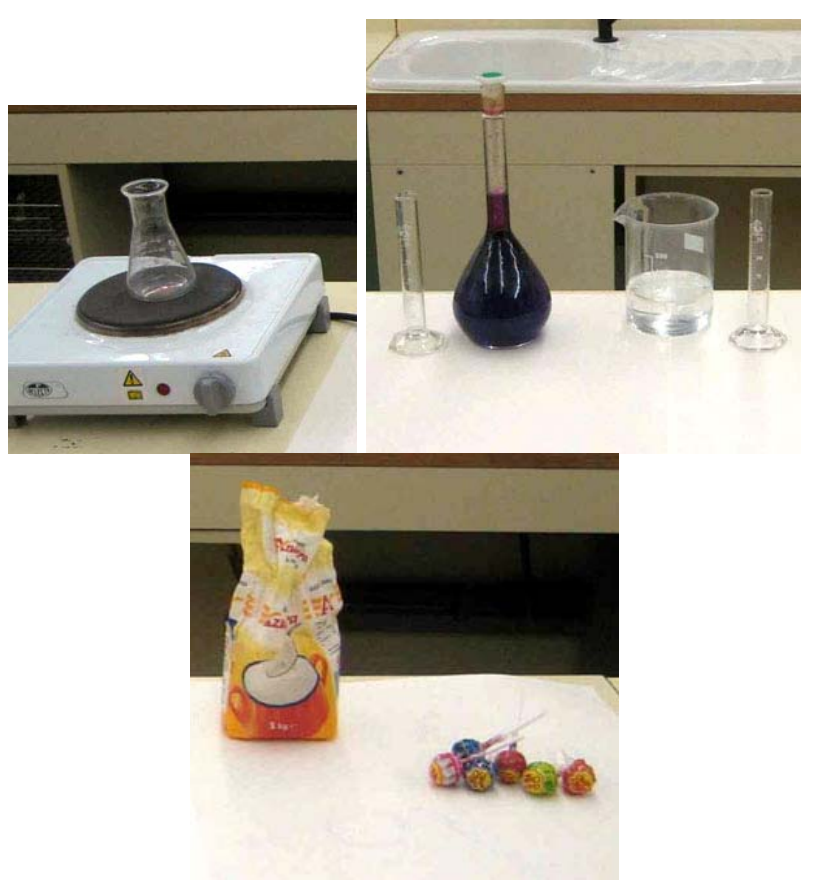

Figura 3. Reactius i material necessari.

Per avaluar els diferents efectes, proposem realitzar les següents experiències.

\section{A. Efecte de la temperatura}

Prepararem dues mostres de reacció amb les mateixes quantitats de reactius. Una l'escalfarem i 
l'altra no. Al final compararem el temps que triguen per reaccionar.

\section{Procediment}

Mesurem amb una proveta $20 \mathrm{~mL}$ de la solució de permanganat, $20 \mathrm{~mL}$ de la solució d'àcid i 2 grams de sucre, ho posem en l'erlenmeyer. En posem una a escalfar en el fogó elèctric i l'altra la deixem a temperatura ambient. Mesurem el temps que triguen a reaccionar.

\section{B. Efecte de l'estat físic dels reactius}

Preparem dues mostres de reacció idèntiques, la diferència és que en una el sucre l'introduïm en forma de sòlid i en l'altra en forma de dissolució. Al final comparem els temps que triguen a reaccionar.

\section{Procediment}

Mesurem amb una proveta $20 \mathrm{~mL}$ de la solució de permanganat, $20 \mathrm{~mL}$ de la solució d'àcid, 1 gram de sucre, i $10 \mathrm{~mL}$ d'aigua. Ho posem en un matràs Erlenmeyer (bomex) i simultàniament preparem una mostra idèntica en què el sucre s'ha desfet prèviament. Les posem a escalfar totes dues al fogó elèctric i mesurem el temps que cadascuna triga a reaccionar.

\section{Efecte del grau de divisió dels reactius}

Preparem dues mostres de reacció gairebé idèntiques, amb la diferència que en una el sucre l'introduïm sòlid cristal.lí i en l'altre en forma de xupa-xup. Al final comparem els temps que triguen a reaccionar.

\section{Procediment}

Mesurem amb una proveta $20 \mathrm{~mL}$ de la solució de permanganat, $10 \mathrm{~mL}$ de la solució d'àcid, 1 gram de sucre, i $20 \mathrm{~mL}$ d'aigua. Ho posem en un matràs Erlenmeyer (bomex) i simultàniament preparem una mostra idèntica en què el sucre s'introdueix en forma de xupa-xup. Les posem a escalfar totes dues al fogó elèctric i mesurem el temps que cadascuna triga a reaccionar.

\section{Efecte de la concentració dels reactius}

Preparem quatre mostres de reacció idèntiques en tot, excepte en la concentració del sucre; en la primera posarem $0,5 \mathrm{~g}$ de sucre en $10 \mathrm{~mL}$ d'aigua; en la segona $1 \mathrm{~g}$; en la tercera $2 \mathrm{~g}$; i en la quarta 4 grams.

\section{Procediment}

Mesurem amb una proveta $20 \mathrm{~mL}$ de la solució de permanganat, $20 \mathrm{~mL}$ de la solució d'àcid, i afegim la solució de sucre, les posem a escalfar totes quatre simultàniament i mesurem els temps que triguen a reaccionar.

\section{Resultats}

Els resultats d'aquesta experiència són els temps que triguen a reaccionar les diferents mostres. Els resultats depenen de la intensitat que escalfem. Nosaltres escalfem de forma suau i progressiva per evitar accidents i poder veure diferències de temps significatives.

a) En l'efecte de la temperatura la mostra que no s'escalfa no reacciona en tota l'hora que dura la pràctica, mentre que l'altra triga 185 s a reaccionar.

b) En l'efecte de l'estat físic dels reactius la que porta el sucre dissolt, triga $140 \mathrm{~s}$ a reaccionar i l'altra, $192 \mathrm{~s}$.

c) En l'efecte del grau de divisió dels reactius, la del xupa-xup, triga $210 \mathrm{~s}$ i la del sucre, $179 \mathrm{~s}$.
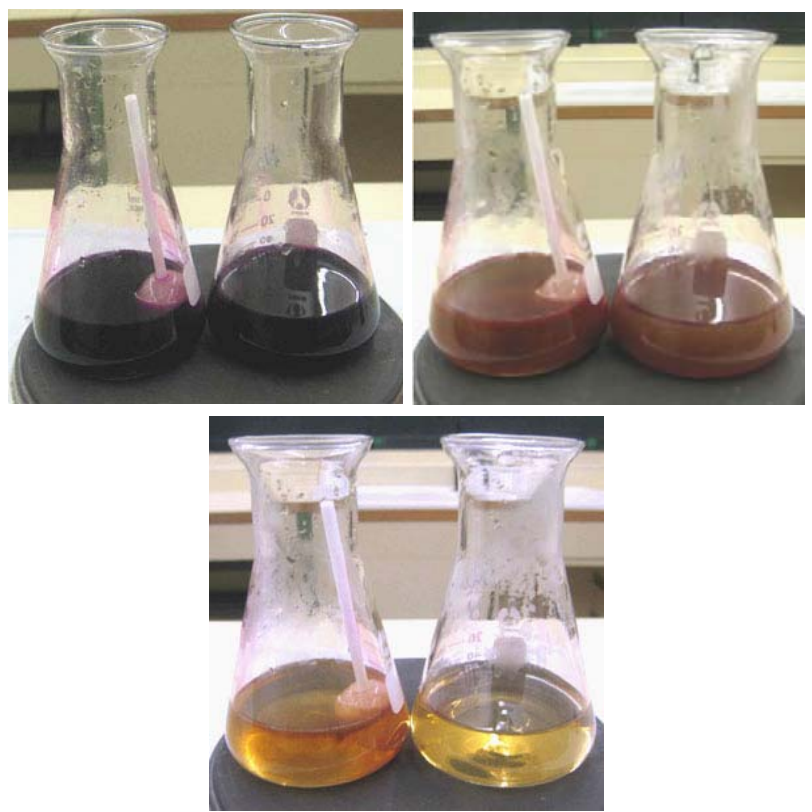

Figura 4. En la seqüència de tres imatges podem apreciar els canvis de color que van tenint lloc en la reacció. 
d) En l'efecte de la concentració, les dades que obtenim són:

\begin{tabular}{|l|c|c|c|c|}
\hline g sucre / $10 \mathrm{~mL}$ & 0,5 & 1 & 2 & 4 \\
\hline temps (s) & 180 & 165 & 155 & 148 \\
\hline
\end{tabular}

\section{Conclusions}

Comparant els resultats de temps concloem:

a) La reacció té una barrera d'activació i la temperatura augmenta la velocitat de reacció.

b) Els reactius en estat líquid, clarament reaccionen més ràpidament que els que estan en estat sòlid.

c) Quant més finament està dividit el reactiu, més ràpidament reacciona.

d) Quant augmentem la concentració dels reactius augmenta la velocitat de reacció, encara que en aquest cas no és ben lineal (potser degut al fet que la temperatura també augmenta amb el temps $\mathrm{i}$ el fogó té una inèrcia tèrmica).

\section{Residus}

Els residus de tots els processos que hem anat fent els podem recollim en un erlenmeyer de $0,5 \mathrm{~L}$. És un residu àcid transparent que conté $\mathrm{Mn}^{2+}$ en solució.

Per desactivar el residu cal afegir unes gotes de fenolftaleïna i neutralitzar amb hidròxid de sodi 1 $\mathrm{mol} / \mathrm{L}$ fins al viratge de la fenolftaleïna. El residu es pot guardar en el recipient de sals neutralitzades.

També és interessant comentar als alumnes que el permanganat de potassi, tot i el seu aspecte havia estat utilitzat en la potabilització d'aigües com a agent oxidant, que ajudava a eliminar, tot oxidantles, les restes de matèria orgànica que propiciaven el desenvolupament bacterià.

\section{Referències bibliogràfiques}

Mahan.(1988). Química. Fondo Educativo Interamericano.

Sanmartí, Neus.(2002). Didàctica de las ciencias en la educación secundaria obligatoria. Síntesis educación.

Totes les fotografies són obra de l'autor. 